\title{
Influence of CYP2C19 on Helicobacter pylori eradication in Brazilian patients with functional dyspepsia
}

D.D. Nabinger ${ }^{1}$, L.E. Mazzoleni² ${ }^{2}$ G.B. Sander ${ }^{2}$, F. Mazzoleni², M.C. Osório ${ }^{1}$, M.G. Klein ${ }^{1}$, T.F. Rech ${ }^{1}$, L. Basso da Silva ${ }^{3}$, G.S. de Moraes $^{2}$, R.A. Cristovam², E.F. Nardelli ${ }^{2}$, C.F.M. Francesconi ${ }^{2}$ and D. Simon ${ }^{1}$

${ }^{1}$ Laboratório de Genética Molecular Humana, Universidade Luterana do Brasil, Canoas, RS, Brasil

${ }^{2}$ Serviço de Gastroenterologia, Hospital de Clínicas de Porto Alegre, Porto Alegre, RS, Brasil

${ }^{3}$ Instituto de Ciências da Saúde, Universidade FEEVALE,

Novo Hamburgo, RS, Brasil

Corresponding author: D. Simon

E-mail: daniel.simon@ulbra.br

Genet. Mol. Res. 15 (3): gmr.15038734

Received April 27, 2016

Accepted June 14, 2016

Published September 16, 2016

DOI http://dx.doi.org/10.4238/gmr.15038734

Copyright $(2016$ The Authors. This is an open-access article distributed under the terms of the Creative Commons Attribution ShareAlike (CC BY-SA) 4.0 License

ABSTRACT. The aim of this study was to examine the effect of polymorphisms in the cytochrome P450 (CYP) 2C19 gene (CYP2C19) on the Helicobacter pylori eradication rate in Brazilian patients with functional dyspepsia. Adults diagnosed with functional dyspepsia based on the ROME III criteria and infected with $H$. pylori were recruited to this study. The patients were subjected to gastrointestinal endoscopy and the $H$. pylori status was defined when both urease test and histopathology results were negative or positive. The patients were treated with proton pump inhibitor-based triple therapy (omeprazole, 
amoxicillin, and clarithromycin). CYP2C19*2 and $C Y P 2 C 19 * 3$ were genotyped by polymerase chain reaction-restriction fragment length polymorphism. One hundred and forty-eight patients ( $81.8 \%$ women) with a mean ( \pm SD) age of 46.1 (12.2) years were included in this study. Based on the CYP2C19 genotypes, the patients were classified as homozygous extensive metabolizer (HomEM; 67.6\%), heterozygous extensive metabolizer (HetEM; 26.3\%), or poor metabolizer(PM; 6.1\%). The H. pylori eradication rates in patients with HomEM, HetEM, and PM were 85.0, 89.7, and $100.0 \%(\mathrm{P}=0.376)$, respectively. The included study population comprised a high frequency of patients carrying the HomEM genotype. Although the genotypes of CYP2C19 variants were not statistically significant, the results of this study suggest a possible effect of the PM genotype on the efficacy of $H$. pylori eradication.

Key words: Cytochrome P450 CYP2C19; Helicobacter pylori eradication; Functional dyspepsia; Poor metabolizer genotype

\section{INTRODUCTION}

Helicobacter pylori infection is associated with chronic gastritis, peptic ulcer disease, mucosa-associated lymphoid tissue lymphoma, and gastric adenocarcinoma (Wotherspoon, 1998; Marshall and Windsor, 2005; McColl, 2010). The prevalence of $H$. pylori infection in patients with functional dyspepsia (FD) has been reported to be in the range of 40 to $70 \%$ (Talley, 1994; Egan et al., 2007). The recommended treatment method in such patients is the eradication of $H$. pylori, which could relieve the symptoms of FD and help prevent other gastric complications (Mazzoleni et al., 2011; Malfertheiner et al., 2012). Some studies have reported a lower H. pylori eradication rate in patients with FD than that in patients with other gastric disorders such as peptic ulcer disease (Jones and Lydeard, 1989; Jones et al., 1990).

Dyspepsia is a common complaint in gastroenterology practice, with a prevalence rate of $\sim 30 \%$ (Tack et al., 2006). Most affected individuals do not have structural or biochemical abnormalities that can explain their symptoms and are, therefore, diagnosed with functional or non-ulcer dyspepsia (Fuccio et al., 2008). The symptoms have a major impact on the quality of life of FD patients, often prompting them to seek medical advice, which represents $\sim 3-4 \%$ of all general practitioner consultations (Tack et al., 2006). Dyspepsia is also the most common source of referrals to gastroenterologists, imposing a huge economic burden on the individual and budgets of many countries through decreased work productivity and missed workdays (Sander et al., 2011; Matsuhisa and Tsukui, 2014).

The most common therapeutic regimens for the eradication of $H$. pylori include the concomitant use of proton pump inhibitors (PPIs) and antibiotic agents, resulting in eradication rates of 80 to $90 \%$ (Tang et al., 2013). PPIs are mostly metabolized by the cytochrome P450 (CYP) enzyme system, particularly the CYP2C19 enzyme (Ishizaki and Horai, 1999). The CYP2C19 gene is highly polymorphic, with several functional polymorphisms or alleles that can influence the pharmacokinetics and pharmacodynamics of PPIs (Furuta et al., 2005). The wild-type allele, $C Y P 2 C 19 * 1$, translates into an enzyme with high activity. $C Y P 2 C 19 * 2$ and CYP 2 C19*3, however, are the most commonly reported alleles and may be involved in interindividual variability of drug metabolism (Hunfeld et al., 2010).

Genetics and Molecular Research 15 (3): gmr.15038734 
CYP2C19*2 (rs4244285) is a defective allele that carries a single nucleotide polymorphism $(681 \mathrm{G} \rightarrow \mathrm{A})$ in exon 5 , resulting in an aberrant splice site. CYP2C19*3 (rs4986893) undergoes a G-to-A transition $(636 \mathrm{G} \rightarrow \mathrm{A})$ in exon 4 , leading to a premature stop codon. These mutations encode a non-functional protein, dramatically decreasing drug metabolism (De Morais et al., 1994a,b; Hirota et al., 2013). The CYP2C19 phenotype can be categorized as extensive metabolizer (EM) or poor metabolizer (PM) (Ishizaki and Horai, 1999). The homozygous EM (HomEM) has two wild-type alleles $(* 1 / * 1)$ that have a functional enzyme, thereby accelerating the PPI metabolism. The heterozygous EM (HetEM) genotype carries one wild-type allele and one loss-of-function variant allele $(* 1 / * 2$ or $* 1 / * 3)$, translating into an enzyme with intermediate functional capacity. The PM genotype comprises two loss-of-function variant alleles $(* 2 / * 2$, $* 2 / * 3$, or *3/*3) (Padol et al., 2006); therefore, individuals with the PM genotypes display a much slower PPI metabolism rate. This leads to higher PPI bioavailability (approximately 13 higher than that seen in HomEM individuals) (Furuta et al., 2005).

The aim of this study was to examine the prevalence of the CYP2C19 variant genotypes and their influence on the H. pylori eradication rate in patients with FD treated with clarithromycin, amoxicillin, and omeprazole for 10 days.

\section{MATERIAL AND METHODS}

\section{Patients}

Patients with FD were selected for this study from the sample population included in the Helicobacter Eradication Relief of Dyspeptic Symptoms Trial (HEROES Trial, ClinicalTrials.gov No. NCT00404534). The HEROES Trial is a randomized double-blind, placebo-controlled clinical trial carried out at Hospital de Clínicas de Porto Alegre, Porto Alegre, Brazil (Mazzoleni et al., 2011). Briefly, community and primary care patients of either gender who were 18 years of age or older diagnosed with FD according to the Roma III criteria (Fuccio et al., 2008), and who tested positive for $\mathrm{H}$. pylori by histological and biochemical diagnostic tests were enrolled in the trial. Patients who had used antibiotics or bismuth 4 weeks before enrollment, PPIs 2 weeks before enrollment, or those treated with histamine-2 receptor blockers in the week before enrollment were excluded. The complete exclusion criteria have been described in detail elsewhere (Mazzoleni et al., 2011).

Upper gastrointestinal endoscopies were performed at screening and at least 12 months after screening. Three biopsy specimens were obtained from the body of the stomach, three from the antrum, and two from the incisura angularis. The H. pylori status was defined when the results of both the urease test and histopathological examination were negative or positive for infection (stains: Giemsa and hematoxylin-eosin). A third pathologist was consulted in case of disagreement between the primary pathologists.

Eligible patients enrolled in the HEROES Trial were randomly assigned to receive the omeprazole (20 mg twice daily), amoxicillin (1000 $\mathrm{mg}$ twice daily), and clarithromycin (500 mg twice daily) (Omepramix ${ }^{\circledR}$; Aché Laboratórios Farmacêuticos SA, São Paulo, SP, Brazil) treatment for 10 days (antibiotics group) or omeprazole (20 $\mathrm{mg}$ twice daily) and placebo antibiotic (control group) treatment. Adherence to study medication was assessed by the pill count of returned medication. Patients were considered to be adherent if at least $80 \%$ of the prescribed medications for $H$. pylori eradication were consumed.

Genetics and Molecular Research 15 (3): gmr.15038734 
In this study, we examined the prevalence of CYP2C19 variants and their role in $H$. pylori eradication rate in patients belonging to the antibiotics group. Patients who agreed to participate in genetic studies were included in this study. DNA was extracted from the stored blood samples for subsequent analysis of CYP2C19 polymorphisms. The study protocol was approved by the local Institutional Review Board and informed consent was obtained from all patients prior to enrollment.

\section{Genetic analysis}

Genomic DNA was extracted from blood samples using a salting-out method (Lahiri and Nurnberger, 1991). The variant genotypes of the CYP2C19*2 $(681 \mathrm{G} \rightarrow \mathrm{A}$; rs4244285) and $C Y P 2 C 19 * 3(636 \mathrm{G} \rightarrow \mathrm{A}$; rs4986893) polymorphisms were detected by polymerase chain reaction-restriction fragment length polymorphism (PCR-RFLP), using previously described primers and conditions (De Morais et al., 1994a,b; Kubota et al., 1996). The amplified 168-bp (for $C Y P 2 C 19 * 2$ ) and 119-bp (for CYP2C19*3) PCR products were digested with MspI and $B a m H I$ restriction endonucleases, respectively, and subsequently separated and analyzed in $10 \%$ polyacrylamide gels stained with silver nitrate.

Patients were classified according to their $C Y P 2 C 19$ genotypes, as follows: HomEM, homozygous for the wild-type allele (CYP2C19*1/CYP2C19*1); HetEM, heterozygous for CYP2C19*2 or CYP2C19*3 (CYP2C19*1/CYP2C19*2 or CYP2C19*1/CYP2C19*3); and $\mathrm{PM}$, homozygous for $C Y P 2 C 19 * 2$ or $C Y P 2 C 19 * 3$ or compound heterozygous $(C Y P 2 C 19 * 2$ ) $C Y P 2 C 19 * 2$ or $C Y P 2 C 19 * 3 / C Y P 2 C 19 * 3$ or $C Y P 2 C 19 * 2 / C Y P 2 C 19 * 3)$.

\section{Statistical analysis}

Allele frequencies were determined by direct count of alleles, and deviations from Hardy-Weinberg equilibrium were evaluated by the chi-square test. Associations between categorical variables were tested using the chi-square or Fisher exact tests. Continuous variables were analyzed by the Student $t$-test or Mann-Whitney $U$ test. Data analysis was conducted using SPSS v.18.0 (SPSS Inc., Chicago, IL, USA). A two-tailed P value $<0.05$ was considered statistically significant.

\section{RESULTS}

A total of 404 patients were recruited for the intention-to-treat analysis in the HEROES Trial. Of these, 303 patients consented to participate in genetic studies (154 in the control group and 149 in the antibiotics group). One patient in the antibiotics group was lost to followup (Figure 1) because of missing data.

In this study, we analyzed $148 \mathrm{H}$. pylori-positive patients with FD (121 women, $81.8 \%$; 27 men, 19.2\%) with a mean (SD) age of 46.1 (12.2) years. All patients completed the study; the adherence to study medication was $94.6 \%$. The baseline characteristics of the included patients are shown in Table 1.

Of the 148 patients, 100 (67.6\%) had the HomEM genotype, 39 (26.3\%) had the HetEM genotype, and $9(6.1 \%)$ had the PM genotype. The overall $H$. pylori-eradication rate was $129 / 148(87.2 \%)$. The $H$. pylori-eradication rates in the HomEM, HetEM, and PM groups were $85.0,89.7$, and $100.0 \%$, respectively $(\mathrm{P}=0.376)$ (Table 2$)$.

Genetics and Molecular Research 15 (3): gmr.15038734 


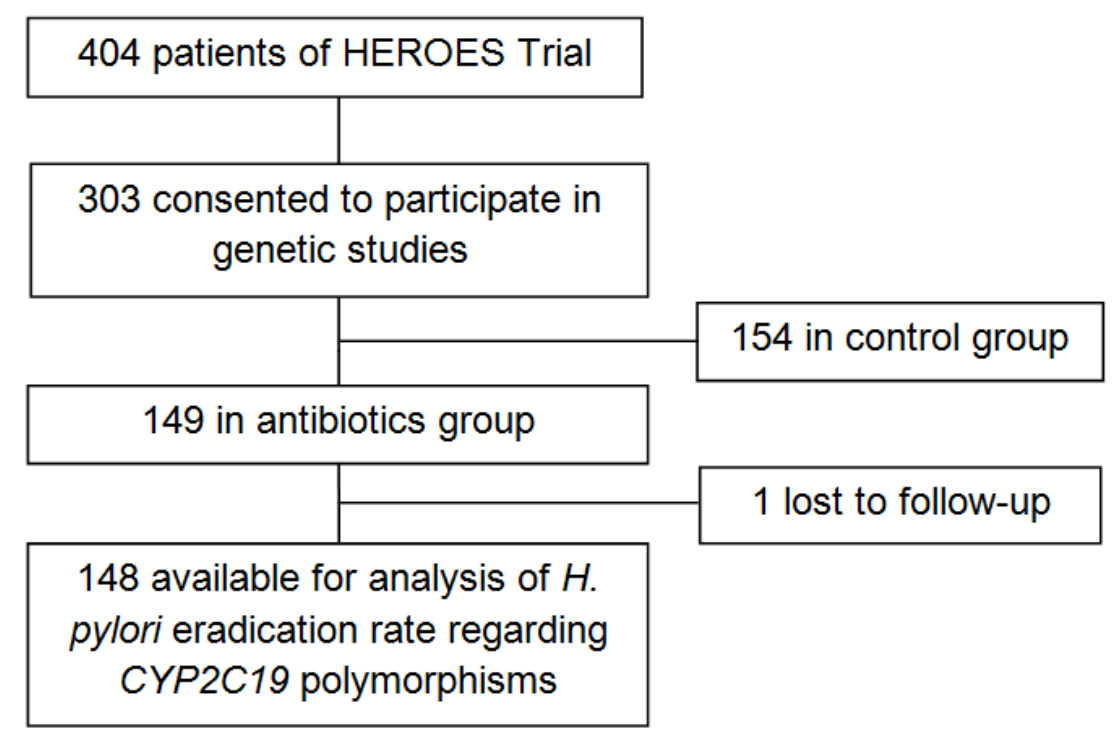

Figure 1. Flow chart depicting study participants.

Table 1. Baseline characteristics of patients with functional dyspepsia $(\mathrm{N}=148)$.

\begin{tabular}{l|c}
\hline Variable & $\mathrm{N}(\%)$ \\
\hline Age (mean \pm SD, years) & $46.1 \pm 12.2$ \\
\hline Female & $121(81.8)$ \\
\hline Caucasian ethnicity & $117(79.1)$ \\
\hline Education & $89(60.2)$ \\
\hline$\leq 10$ years & $59(39.8)$ \\
\hline$>10$ years & $85(57.4)$ \\
\hline Smoking status & $36(24.3)$ \\
\hline Never smoked & $27(18.2)$ \\
\hline Former & $127(85.8)$ \\
\hline Current & $4(2.7)$ \\
\hline Alcohol consumption & $17(11.5)$ \\
\hline No consumption & $98(66.2)$ \\
\hline Former &
\end{tabular}

Table 2. Genotype frequencies of patients stratified by Helicobacter pylori status post-treatment.

\begin{tabular}{l|c|c|c|c}
\hline Genotype $^{1}$ & Total $(\mathrm{N}=148)$ & H. pylori-negative $(\mathrm{N}=129)$ & H. pylori-positive $(\mathrm{N}=19)$ & $\mathrm{P}$ \\
\hline HomEM & $100(67.6)$ & $85(85.0)$ & $15(15.0)$ & 0.376 \\
\hline HetEM & $39(26.3)$ & $35(89.7)$ & $4(10.3)$ & \\
\hline PM & $9(6.1)$ & $9(100.0)$ & - & \\
\hline
\end{tabular}

${ }^{1}$ HomEM = homozygous extensive metabolizer; HetEM = heterozygous extensive metabolizer; $\mathrm{PM}=$ homozygous poor metabolizer.

Genetics and Molecular Research 15 (3): gmr.15038734 


\section{DISCUSSION}

In this study, we analyzed patients with FD to investigate the influence of the CYP2C19 genotypes on $H$. pylori eradication rate. We observed a high frequency of the HomEM genotype (followed by HetEM) and a low frequency of the PM genotype. H. pylori was eradicated in all PM patients, and the success rate of $H$. pylori treatment was slightly higher in patients with HetEM than that in patients with the HomEM genotype. However, the differences in eradication rates between CYP2C19 genotypes were not statistically significant.

A major strength of this study is that the study population was a well-selected group of patients with FD (diagnosed according to the ROME III criteria) who were positive for H. pylori infection. All patients underwent upper gastrointestinal endoscopy with gastric and duodenal biopsies, and only those who tested positive for $H$. pylori were recruited to the trial. The infection status was rigorously assessed by two pathologists based on the results of the urease test and histopathological examinations; a third pathologist was consulted in case of disagreement. All patients received daily doses of clarithromycin, amoxicillin, and omeprazole (twice each) for 10 days. This treatment period, longer than the usual 7-day treatment period, was chosen because $H$. pylori eradication is less effective in patients with FD than that in patients with other gastric disorders. Additional strengths of this study were that only one patient was not followed-up and high proportion of adherence to study medication was achieved for all participants.

CYP2C19 is an enzyme involved in the metabolism of several clinically used drugs, including some barbiturates, diazepam, proguanil, propranolol, and clopidogrel (Hirota et al., 2013; Liboredo and Pena, 2014). This enzyme is also responsible for the in vivo metabolism of most PPIs, such as omeprazole, lansoprazole, and pantoprazole (Ishizaki and Horai, 1999; Furuta et al., 2005). Genetic polymorphisms in CYP2C19 are associated with increased clinical efficacy of PPI-based triple therapies for $H$. pylori eradication, and they could also be of clinical concern in the treatment of acid-related diseases with PPIs (Ishizaki and Horai, 1999; Zhao et al., 2008). It is known that the rate of PPI clearance (from the circulation) in individuals expressing the PM genotype is slower than that in individuals expressing the HomEM or HetEM genotypes (Zhao et al., 2008; Lee et al., 2014). Studies on the pharmacogenetics, pharmacodynamics, and pharmacokinetics of PPIs have shown that the plasma omeprazole concentrations in patients receiving a single dose of omeprazole differed between those carrying the three different genotype of CYP2C19. Plasma omeprazole levels in individuals with the PM genotype are sustained long after drug administration. Furthermore, the mean values of the areas under the plasma omeprazole concentration-time curves in the PM group are $\sim 13$ times higher than those in the HomEM group (Furuta et al., 2005).

The CYP2C19 genotype frequencies observed in our study are consistent with those of previous studies in Brazilian populations (Suarez-Kurtz et al., 2012). A recent study conducted in Southern Brazil (at the same geographic location sampled in this study) reported HomEM, HetEM, and PM genotype frequencies of 71.5, 26.3, and 2.2\%, respectively (Kohlrausch et al., 2014). Other studies conducted in western populations have also reported similar CYP2C19 genotype distributions (Ishizaki and Horai, 1999; Kurose et al., 2012; Nastasi-Catanese et al., 2013). However, a significantly different distribution was reported in Asian populations, where the frequency of the PM genotype was $\sim 23 \%$ higher than that in western populations (approximately 5\%) (Ishizaki and Horai, 1999; Hirota et al., 2013).

Studies evaluating CYP2C19 variants and $H$. pylori eradication in omeprazole-based

Genetics and Molecular Research 15 (3): gmr.15038734 
regimens have shown conflicting results. While some studies have reported a significant association between H. pylori cure rates and CYP2C19 genotypes (Sheu et al., 2005; Sugimoto et al., 2006; Chaudhry et al., 2009), others have been unable to statistically confirm the association between the CYP2C19 genotypes and successful H. pylori eradication; however, the latter studies have reported a high $H$. pylori eradication rate in individuals carrying the PM genotype, compared to those carrying the EM genotype (Inaba et al., 2002; Sapone et al., 2003; Zhang et al., 2010). These results are similar to the results seen in our sample population; that is, bacteria were eradicated in all (100\%) individuals carrying the PM genotype, although statistical significance was not achieved. It is worth noting that several meta-analyses have reported a significant association between the CYP2C19 genotypes and $H$. pylori eradication rates (Padol et al., 2006; Zhao et al., 2008; Tang et al., 2013).

PPI, clarithromycin, and amoxicillin or metronidazole triple therapy has been the universally recommended treatment method for $H$. pylori-infection, since its proposal at the First Maastricht conference (Malfertheiner et al., 1997). Recent studies have indicated the decreased efficacy of this combination over the years, resulting $H$. pylori-eradication rates of $<70 \%$ (Malfertheiner et al., 2012). The reduced efficacy of standard triple therapy has been attributed to antibiotic resistance (Furuta et al., 2005; Lee et al., 2014). Recent years have seen the emergence of a few amoxicillin-resistant $H$. pylori strains; however, the major limiting factor of PPI-amoxicillin-clarithromycin triple therapy is the resistance of recent $H$. pylori strains to clarithromycin (Furuta et al., 2005). H. pylori shows varied antibiotic susceptibility patterns in various geographical locations; moreover, this bacterium has been substantially influenced by the prior use of these drugs (Han et al., 1999). Previous studies conducted in Brazil have reported varying rates of $\mathrm{H}$. pylori resistance to clarithromycin, ranging from 11.1 to $17.3 \%$ (Prazeres Magalhães et al., 2002; Eisig et al., 2011; Picoli et al., 2014). In this study, we could not show an association between the CYP2C19 genotype and efficacy of $H$. pylori eradication; however, $H$. pylori eradication was observed in a large proportion of patients (87.2\%). This may be attributed to the low rates of clarithromycin resistance in H. pylori strains in Brazil, as well as the high patient compliance and prolonged treatment time of this study.

The results of this study are subject to certain limitations. The statistical power to detect differences was limited by the small sample size and low frequency of individuals carrying the PM genotype. Additionally, the CYP2C19 gene shows great variability, with more than 30 alleles being identified, some of which have been classified as ultrarapid metabolizers $\left(C Y P 2 C 19^{*} 17\right)$. This increases the complexity of genotype-phenotype studies investigating the CYP2C19 gene. In this study, the most commonly reported CYP2C19 variants were analyzed.

In conclusion, no association was found between the CYP2C19 genotype variants and $H$. pylori eradication rates. However, the results suggest a possible role of the PM genotype in determining the efficacy of $H$. pylori eradication. Therefore, we suggest that the dosage of PPI (in triple therapy) could be increased in populations with a high frequency of individuals carrying the EM genotype.

\section{Conflicts of interest}

The authors declare no conflict of interest.

\section{ACKNOWLEDGMENTS}

The drugs and the gastroscope used in this study were obtained by an unrestricted

Genetics and Molecular Research 15 (3): gmr.15038734 
donation from Aché Laboratórios Farmacêuticos SA, São Paulo, SP, Brazil. Research partially supported by the HCPA Institutional Research Fund (FIPE-HCPA).

\section{REFERENCES}

Chaudhry AS, Kochhar R and Kohli KK (2009). Importance of CYP2C19 genetic polymorphism in the eradication of Helicobacter pylori in north Indians. Indian J. Med. Res. 130: 437-443.

De Morais SM, Wilkinson GR, Blaisdell J, Meyer UA, et al. (1994a). Identification of a new genetic defect responsible for the polymorphism of (S)-mephenytoin metabolism in Japanese. Mol. Pharmacol. 46: 594-598.

De Morais SM, Wilkinson GR, Blaisdell J, Nakamura K, et al. (1994b). The major genetic defect responsible for the polymorphism of S-mephenytoin metabolism in humans. J. Biol. Chem. 269: 15419-15422.

Egan BJ, Katicic M, O'Connor HJ and O’Morain CA (2007). Treatment of Helicobacter pylori. Helicobacter 12 (Suppl 1): 31-37. http://dx.doi.org/10.1111/j.1523-5378.2007.00538.x

Eisig JN, Silva FM, Barbuti RC, Navarro-Rodriguez T, et al. (2011). Helicobacter pylori antibiotic resistance in Brazil: clarithromycin is still a good option. Arq. Gastroenterol. 48: 261-264. http://dx.doi.org/10.1590/S000428032011000400008

Fuccio L, Laterza L, Zagari RM, Cennamo V, et al. (2008). Treatment of Helicobacter pylori infection. BMJ 337: a1454. http://dx.doi.org/10.1136/bmj.a1454

Furuta T, Shirai N, Sugimoto M, Nakamura A, et al. (2005). Influence of CYP2C19 pharmacogenetic polymorphism on proton pump inhibitor-based therapies. Drug Metab. Pharmacokinet. 20: 153-167. http://dx.doi.org/10.2133/dmpk.20.153

Han SR, Bhakdi S, Maeurer MJ, Schneider T, et al. (1999). Stable and unstable amoxicillin resistance in Helicobacter pylori: should antibiotic resistance testing be performed prior to eradication therapy? J. Clin. Microbiol. 37: 2740-2741.

Hirota T, Eguchi S and Ieiri I (2013). Impact of genetic polymorphisms in CYP2C9 and CYP2C19 on the pharmacokinetics of clinically used drugs. Drug Metab. Pharmacokinet. 28: 28-37. http://dx.doi.org/10.2133/dmpk.DMPK-12-RV-085

Hunfeld NG, Touw DJ, Mathot RA, Mulder PG, et al. (2010). A comparison of the acid-inhibitory effects of esomeprazole and pantoprazole in relation to pharmacokinetics and CYP2C19 polymorphism. Aliment. Pharmacol. Ther. 31: 150159. http://dx.doi.org/10.1111/j.1365-2036.2009.04150.x

Inaba T, Mizuno M, Kawai K, Yokota K, et al. (2002). Randomized open trial for comparison of proton pump inhibitors in triple therapy for Helicobacter pylori infection in relation to CYP2C19 genotype. J. Gastroenterol. Hepatol. 17: 748-753. http://dx.doi.org/10.1046/j.1440-1746.2002.02790.x

Ishizaki T and Horai Y (1999). Review article: cytochrome P450 and the metabolism of proton pump inhibitors--emphasis on rabeprazole. Aliment. Pharmacol. Ther. 13 (Suppl 3): 27-36. http://dx.doi.org/10.1046/j.1365-2036.1999.00022.x

Jones R and Lydeard S (1989). Prevalence of symptoms of dyspepsia in the community. BMJ 298: 30-32. http://dx.doi. org/10.1136/bmj.298.6665.30

Jones RH, Lydeard SE, Hobbs FD, Kenkre JE, et al. (1990). Dyspepsia in England and Scotland. Gut 31: 401-405. http:// dx.doi.org/10.1136/gut.31.4.401

Kohlrausch FB, Carracedo Á and Hutz MH (2014). Characterization of CYP1A2, CYP2C19, CYP3A4 and CYP3A5 polymorphisms in South Brazilians. Mol. Biol. Rep. 41: 1453-1460. http://dx.doi.org/10.1007/s11033-013-2990-8

Kubota T, Chiba K and Ishizaki T (1996). Genotyping of S-mephenytoin 4'-hydroxylation in an extended Japanese population. Clin. Pharmacol. Ther. 60: 661-666. http://dx.doi.org/10.1016/S0009-9236(96)90214-3

Kurose K, Sugiyama E and Saito Y (2012). Population differences in major functional polymorphisms of pharmacokinetics/ pharmacodynamics-related genes in Eastern Asians and Europeans: implications in the clinical trials for novel drug development. Drug Metab. Pharmacokinet. 27: 9-54. http://dx.doi.org/10.2133/dmpk.DMPK-11-RV-111

Lahiri DK and Nurnberger JI, Jr. (1991). A rapid non-enzymatic method for the preparation of HMW DNA from blood for RFLP studies. Nucleic Acids Res. 19: 5444. http://dx.doi.org/10.1093/nar/19.19.5444

Lee JY, Kim N, Kim MS, Choi YJ, et al. (2014). Factors affecting first-line triple therapy of Helicobacter pylori including CYP2C19 genotype and antibiotic resistance. Dig. Dis. Sci. 59: 1235-1243. http://dx.doi.org/10.1007/s10620-014-3093-7

Liboredo R and Pena SD (2014). Pharmacogenomics: accessing important alleles by imputation from commercial genomewide SNP arrays. Genet. Mol. Res. 13: 5713-5721. http://dx.doi.org/10.4238/2014.July.25.27

Malfertheiner P, Mégraud F, O’Morain C, Bell D, et al.; The European Helicobacter pylori Study Group (EHPSG) (1997). Current European concepts in the management of Helicobacter pylori infection--the Maastricht Consensus Report. Eur. J. Gastroenterol. Hepatol. 9: 1-2. http://dx.doi.org/10.1097/00042737-199701000-00002

Malfertheiner P, Megraud F, O'Morain CA, Atherton J, et al.; European Helicobacter Study Group (2012). Management of Helicobacter pylori infection - the Maastricht IV/ Florence Consensus Report. Gut 61: 646-664. http://dx.doi.

Genetics and Molecular Research 15 (3): gmr.15038734 
org/10.1136/gutjnl-2012-302084

Marshall BJ and Windsor HM (2005). The relation of Helicobacter pylori to gastric adenocarcinoma and lymphoma: pathophysiology, epidemiology, screening, clinical presentation, treatment, and prevention. Med. Clin. North Am. 89: 313-344, viii. http://dx.doi.org/10.1016/j.mcna.2004.09.001

Matsuhisa T and Tsukui T (2014). The first-line eradication rate for Helicobacter pylori infection in functional dyspepsia patients. J. Gastroenterol. Hepatol. Res. 3: 1156-1161.

Mazzoleni LE, Sander GB, Francesconi CF, Mazzoleni F, et al. (2011). Helicobacter pylori eradication in functional dyspepsia: HEROES trial. Arch. Intern. Med. 171: 1929-1936. http://dx.doi.org/10.1001/archinternmed.2011.533

McColl KE (2010). Clinical practice. Helicobacter pylori infection. N. Engl. J. Med. 362: 1597-1604. http://dx.doi. org/10.1056/NEJMcp 1001110

Nastasi-Catanese JA, Padilla-Gutiérrez JR, Valle Y, Ortega-Gutiérrez F, et al. (2013). Genetic contribution of CYP2C9, CYP2C19, and APOE variants in acenocoumarol response. Genet. Mol. Res. 12: 4413-4421. http://dx.doi. org $/ 10.4238 / 2013$.October.10.7

Padol S, Yuan Y, Thabane M, Padol IT, et al. (2006). The effect of CYP2C19 polymorphisms on H. pylori eradication rate in dual and triple first-line PPI therapies: a meta-analysis. Am. J. Gastroenterol. 101: 1467-1475. http://dx.doi. org/10.1111/j.1572-0241.2006.00717.x

Picoli SU, Mazzoleni LE, Fernández H, De Bona LR, et al. (2014). Resistance to amoxicillin, clarithromycin and ciprofloxacin of Helicobacter pylori isolated from Southern Brazil patients. Rev. Inst. Med. Trop. Sao Paulo 56: 197200. http://dx.doi.org/10.1590/S0036-46652014000300003

Prazeres Magalhães P, De Magalhães Queiroz DM, Campos Barbosa DV, Aguiar Rocha G, et al. (2002). Helicobacter pylori primary resistance to metronidazole and clarithromycin in Brazil. Antimicrob. Agents Chemother. 46: 20212023. http://dx.doi.org/10.1128/AAC.46.6.2021-2023.2002

Sander GB, Mazzoleni LE, Francesconi CF, Balbinotto G, et al.; Helicobacter Eradication Relief of Dyspetic Symptoms Trial Investigators (2011). Influence of organic and functional dyspepsia on work productivity: the HEROES-DIP study. Value Health 14 (Suppl 1): S126-S129. http://dx.doi.org/10.1016/j.jval.2011.05.021

Sapone A, Vaira D, Trespidi S, Perna F, et al. (2003). The clinical role of cytochrome p450 genotypes in Helicobacter pylori management. Am. J. Gastroenterol. 98: 1010-1015. http://dx.doi.org/10.1111/j.1572-0241.2003.07427.x

Sheu BS, Kao AW, Cheng HC, Hunag SF, et al. (2005). Esomeprazole $40 \mathrm{mg}$ twice daily in triple therapy and the efficacy of Helicobacter pylori eradication related to CYP2C19 metabolism. Aliment. Pharmacol. Ther. 21: 283-288. http:// dx.doi.org/10.1111/j.1365-2036.2005.02281.x

Suarez-Kurtz G, Genro JP, de Moraes MO, Ojopi EB, et al. (2012). Global pharmacogenomics: Impact of population diversity on the distribution of polymorphisms in the CYP2C cluster among Brazilians. Pharmacogenomics J. 12: 267-276. http://dx.doi.org/10.1038/tpj.2010.89

Sugimoto M, Furuta T, Shirai N, Ikuma M, et al. (2006). Influences of proinflammatory and anti-inflammatory cytokine polymorphisms on eradication rates of clarithromycin-sensitive strains of Helicobacter pylori by triple therapy. Clin. Pharmacol. Ther. 80: 41-50. http://dx.doi.org/10.1016/j.clpt.2006.03.007

Tack J, Talley NJ, Camilleri M, Holtmann G, et al. (2006). Functional gastroduodenal disorders. Gastroenterology 130: 1466-1479. http://dx.doi.org/10.1053/j.gastro.2005.11.059

Talley NJ (1994). A critique of therapeutic trials in Helicobacter pylori-positive functional dyspepsia. Gastroenterology 106: 1174-1183. http://dx.doi.org/10.1016/0016-5085(94)90007-8

Tang HL, Li Y, Hu YF, Xie HG, et al. (2013). Effects of CYP2C19 loss-of-function variants on the eradication of H. pylori infection in patients treated with proton pump inhibitor-based triple therapy regimens: a meta-analysis of randomized clinical trials. PLoS One 8: e62162. http://dx.doi.org/10.1371/journal.pone.0062162

Wotherspoon AC (1998). Helicobacter pylori infection and gastric lymphoma. Br. Med. Bull. 54: 79-85. http://dx.doi. org/10.1093/oxfordjournals.bmb.a011683

Zhang L, Mei Q, Li QS, Hu YM, et al. (2010). The effect of cytochrome P2C19 and interleukin-1 polymorphisms on $H$. pylori eradication rate of 1-week triple therapy with omeprazole or rabeprazole, amoxycillin and clarithromycin in Chinese people. J. Clin. Pharm. Ther. 35: 713-722. http://dx.doi.org/10.1111/j.1365-2710.2009.01140.x

Zhao F, Wang J, Yang Y, Wang X, et al. (2008). Effect of CYP2C19 genetic polymorphisms on the efficacy of proton pump inhibitor-based triple therapy for Helicobacter pylori eradication: a meta-analysis. Helicobacter 13: 532-541. http://dx.doi.org/10.1111/j.1523-5378.2008.00643.x

Genetics and Molecular Research 15 (3): gmr.15038734 